\title{
Chronic obstructive pulmonary disease: A scientometric analysis of Indian publications during 2003-2012
}

\author{
Ritu Gupta, B. M. Gupta ${ }^{1 *}$, M. Mueen² \\ Sri Venkateshwar University, Meerut, 11173 Sector 15, Panchkula, Haryana, ${ }^{2}$ Phcog.Net and SciBiolMed, Bangalore, India
}

\begin{abstract}
Examines 592 publications in Indian chronic obstructive pulmonary disease (COPD) research, as indexed in Scopus database during 2003-2012, witnessing an annual average growth rate of $30.38 \%$ and international collaborative publication share of $12.67 \%$. The global share of Indian COPD research was $1.46 \%$ during 2003-2012, which increased from $1.07 \%$ to $1.72 \%$ from 2003-2007 to 2008-2012. Medicine contributed the largest publications share (77.70\%) in Indian COPD research, followed by biochemistry, genetics and molecular biology (16.89\%), pharmacology, toxicology and pharmaceutics (14.36\%), environment science (2.87\%) and immunology and microbiology (2.70\%) during $2003-2012$. The 10 most productive organizations and authors in Indian COPD research contributed $30.07 \%$ and $17.74 \%$ share each to its cumulative publications output during 2003-2012 and have registered an average productivity per author of 17.8 and 10.50, an average citation impact per paper of 3.57 and 5.36 and an average h-index value of 4.60 and 4.50 . The authors suggest the need to increase India's research efforts, improve its research quality and increase its international collaborative research efforts. India also needs to develop a National COPD Prevention and Control Programme, with a major thrust on setting up infrastructure for early and accurate diagnosis, appropriate treatment and rehabilitation programmes, generating new knowledge in COPD and dissemination of knowledge regarding prevention, diagnosis, treatment and rehabilitation to healthcare providers in India.
\end{abstract}

Keywords: Chronic obstructive airway disease, chronic obstructive lung disease, chronic obstructive pulmonary disease, chronic obstructive respiratory disease

\section{INTRODUCTION}

Chronic obstructive pulmonary disease (COPD) is part of respiratory diseases, which include inflammatory lung disease (including asthma, cystic fibrosis, etc.), obstructive lung diseases, restrictive lung diseases or respiratory track infections (including pneumonia), malignant tumors of the respiratory system, pleural cavity disease, pulmonary vascular disease and pulmonary hyperplasia. ${ }^{[1]}$ COPD has been variously labeled in the past as "chronic obstructive

*Address for correspondence:

E-mail: bmgupta1@yahoo.com

\begin{tabular}{|l|l|}
\hline \multicolumn{2}{|c|}{ Access this article online } \\
\hline Quick Response Code: & Website: \\
\hline & www.jscires.org \\
& \\
\hline
\end{tabular}

lung disease," "chronic obstructive airways disease," "chronic airflow obstruction," "chronic airway (or airflow) limitation (CAL)" or simply as "chronic bronchitis" and "emphysema." [2] COPD is presently accepted as an overall umbrella term for a variety of clinical disorders with chronic bronchitis at the one end and emphysema at the other end of the spectrum. ${ }^{[3]}$ COPD is a common preventable and treatable disease, is characterized by persistent airflow limitation that is usually progressive and associated with an enhanced chronic inflammatory response in the airways and the lung to noxious particles or gases. The CAL characteristic of COPD is caused by the mixture of small airways disease (obstructive bronchiolitis) and parenchymal destruction (emphysema), the relative contributions of which vary from person to person. Chronic inflammation causes structural changes and the narrowing of the small airways. Destruction of the lung parenchyma, also by inflammatory processes leads to the loss of alveolar attachments to the small airways and decreases lung elastic recoil, in turn, these changes 
diminish the ability of the airways to remain open during expiration. Exacerbations and co-morbidities contribute to overall severity of individual patients. The factors associated with damage to the lungs spill into the blood and subsequently cause damage to the heart, skeletal muscles, bones, kidneys and brain. In fact, over two-third of patients with COPD die due to ischemic heart disease, congestive heart failure, hypertension, skeletal muscle dysfunction, weight loss, osteoporosis and kidney failure. Symptoms of COPD include: Dyspnea, chronic cough and chronic sputum production. World-wide the most commonly risk factors are tobacco smoking. Chronic exposure to indoor air pollution due to the burning of biomass fuels in poorly ventilated homes and high levels of ambient air pollution, largely due to motor vehicular and industrial exhausts seem to be the major risk factors for COPD in India. Other risk factors are also not uncommon - occupational exposures (farming, mining, building and construction, stone cutting, leather industry and others), a previous lung tuberculosis, poorly treated chronic asthma, poor nutrition and poor socio-economic status. Outdoor occupational and indoor air pollution - the latter is resulting from the burning of biomass fuels-are other major risk factors. The genetic risk factor that is best documented is a severe heredity deficiency of alpha- 1 anti-trypsin. ${ }^{[3-5]}$ Globally, COPD has emerged as the major cause of morbidity and mortality, expected to become the third most leading cause of death and the fifth leading cause of loss of "disability adjusted life years" as per projection of the Global Burden of Disease Study. ${ }^{[3]}$ According to World Health Organization estimates, 65 million people have moderate to severe COPD. More than 3 million people died of COPD in 2005 corresponding to $5 \%$ of all deaths globally, and it is estimated to be the third leading cause of death by 2030. However, it is known that low-and middle-income countries already shoulder much of the burden of COPD with almost $90 \%$ of COPD deaths taking place in these countries. ${ }^{[6]}$ Rough estimates suggest that there are 30 million COPD patients in India. India contributes a significant and growing percentage of COPD mortality which is estimated to be amongst the highest in the world; that is, more than 64.7 estimated age-standardized death rate per 100,000 among both sexes. This would translate to about 556,000 in case of India $(>20 \%)$ out of the world total of $2,748,000$ annually. ${ }^{[7]}$

\section{Literature Review}

Only few scientometric studies have been conducted in the past on respiratory diseases publications. Among them, García-Río et al. ${ }^{[8]}$ examined the respiratory disease research in European Union, as covered in 38 respiratory journals indexed in MEDLINE database during 1987-1998, with a focus on the number of articles from various countries and their relation with socio-economic data, productivity index, visibility index, expected impact factor and relative impact factor. Rippon et al. ${ }^{\left[{ }^{[9]}\right.}$ investigated 81419 respiratory medicine publications, as covered in SCI during 1996-2001 and these were assigned to 14 subject areas (mainly based on title words) and to 15 Organization for Economic Co-operation and Development countries. Publication outputs were compared with the nation's disease burdens and for the UK, the sources of research funding were investigated. Groneberg-Kloft et al. ${ }^{[10]}$ studied research quantity and quality of two obstructive airway diseases, bronchial asthma and COPD during 20 years period (1987-2006), using Web of Science database. In particular, the research activities of UK and Germany are compared. Chen et al. ${ }^{[11]}$ evaluated the publication output on asthma in children during 1991-2002, using SCI database and focused on language, type of document, country of publications, authorship, publication pattern and the most frequently cited papers. Gupta and Bala ${ }^{[12]}$ examined the asthma research output of India during 1999-2008, using Scopus database and focused on the growth, rank and global publications share, citation impact, share of international collaborative publications (ICPs), contribution of major collaborative partner countries, contribution of various subject fields and characteristics of most productive institutions, authors and high-cited publications.

\section{OBJECTIVES}

The main objective of this study is to analyze the Indian and global research output in COPD during 2003-2012 with a view: (i) to study the global publications share and citation impact of top 15 countries, (ii) to study the Indian publication output, its growth and citation impact; (iii) to study the share of international collaborative papers and the share of India's collaborative partner countries; (iv) to study the distribution of publications by different subject sub-fields and by population age groups; (v) to study the publication productivity and citation impact of top 10 Indian organizations and authors; (vi) to study the media of communication of Indians in most productive journals.

\section{METHODOLOGIES AND SOURCE OF DATA}

The publication data of 15 most productive countries (including India) in COPD were extracted and downloaded from Scopus International Database (http://www.scopus.com) for the 
10 years period (2003-2012). For identifying literature on COPD, a set of keywords was identified and the following search strategy (main strategy) (limiting it to country affiliating tag), was used to search and download publication data resulting in 40669 global records and 592 Indian records in COPD during 2003-2012.

Chronic obstructive pulmonary disease literature was classified according to population age groups based on keywords, such as child, adolescents, adults, middle aged and aged. For analyzing publications by sub-fields, database classification as provided in Scopus database has been used. For analyzing significant institutions, authors and journals, separate search strategies were developed, which later combined with the main search strategy leading to the generation of the desired output. For citations data, 3 years, 2 years and 1 year citation window has been used for computing average citations per paper in COPD research during 2003-2010, 2011 and 2012.

\section{ANALYSIS}

\section{Global Publication Share of Top 20 Most Productive Countries}

The global publication share of top 20 most productive countries in COPD varies from $1.27 \%$ to $24.52 \%$ during
2003-2012. The USA occupying the first rank and contributing the largest publication share $(26.52 \%)$, followed by UK $\left(11.83 \%, 2^{\text {nd }}\right.$ rank $)$, Germany $\left(6.48 \%, 3^{\text {rd }}\right.$ rank $)$, Italy $\left(6.44 \%, 4^{\text {th }}\right.$ rank $)$, Canada $\left(5.68 \%, 5^{\text {th }}\right.$ rank $)$, Spain $(5.29 \%$, $6^{\text {th }}$ rank), The Netherlands $\left(4.78 \%, 7^{\text {th }}\right.$ rank), France $(4.16 \%$, $8^{\text {th }}$ rank $)$, Japan $\left(3.45 \%, 9^{\text {th }}\right.$ rank $)$, China $\left(2.94 \%, 10^{\text {th }}\right.$ rank $)$, Australia $\left(2.88 \%, 11^{\text {th }}\right.$ rank), Switzerland, Belgium, Sweden, Turkey, Brazil, India, Poland, Denmark and Greece (from $1.27 \%$ to $1.96 \%$ publication share and rank from $12^{\text {th }}$ to $\left.20^{\text {th }}\right)$. The publication share has increased in USA by $2.1 \%$, followed by China $(1.13 \%)$, Australia $(0.8 \%)$, Japan (0.75\%), Brazil (0.73\%), India (0.65\%), Spain (0.56\%), Turkey $(0.48 \%)$, Greece $(0.45 \%)$, Canada $(0.40 \%)$, Denmark $(0.36 \%)$, Italy $(0.18 \%)$, The Netherlands $(0.09 \%)$, Switzerland $(0.08 \%)$, Belgium $(0.05 \%)$ and Germany $(0.05 \%)$, as against decrease in France $(0.57 \%)$, Sweden $(0.12 \%)$, UK $(0.11 \%)$ and Poland (0.09\%) from 2003-2007 to 2008-2012 [Table 1].

\section{Indian Publication Output, Growth and Citation Impact}

India has published 592 publications in COPD research during 2003-2012, increasing from 16 publications in 2003 to 116 publications in 2012, registering an annual average growth rate of $30.38 \%$. The cumulative growth of

Table 1: Publication output, share and rank of top 20 countries in COPD during 2003-2012

\begin{tabular}{|c|c|c|c|c|c|c|c|c|c|}
\hline \multirow[t]{2}{*}{ Country } & \multicolumn{3}{|c|}{ Number of paper } & \multicolumn{3}{|c|}{ Share of publications } & \multicolumn{3}{|c|}{ Rank of the countries } \\
\hline & 2003-2007 & 2008-2012 & 2003-2012 & 2003-2007 & 2008-2012 & 2003-2012 & 2003-2007 & 2008-2012 & 2003-2012 \\
\hline USA & 4176 & 6608 & 10,784 & 25.27 & 27.37 & 26.52 & 1 & 1 & 1 \\
\hline UK & 1965 & 2845 & 4810 & 11.89 & 11.78 & 11.83 & 2 & 2 & 2 \\
\hline Germany & 1065 & 1570 & 2635 & 6.45 & 6.50 & 6.48 & 3 & 3 & 3 \\
\hline Italy & 1034 & 1554 & 2588 & 6.26 & 6.44 & 6.36 & 4 & 4 & 4 \\
\hline Canada & 899 & 1409 & 2308 & 5.44 & 5.84 & 5.68 & 5 & 5 & 5 \\
\hline Spain & 820 & 1333 & 2153 & 4.96 & 5.52 & 5.29 & 6 & 6 & 6 \\
\hline Netherlands & 781 & 1163 & 1944 & 4.73 & 4.82 & 4.78 & 7 & 7 & 7 \\
\hline France & 744 & 949 & 1693 & 4.50 & 3.93 & 4.16 & 8 & 8 & 8 \\
\hline Japan & 498 & 907 & 1405 & 3.01 & 3.76 & 3.45 & 9 & 9 & 9 \\
\hline China & 375 & 820 & 1195 & 2.27 & 3.40 & 2.94 & 11 & 10 & 10 \\
\hline Australia & 398 & 775 & 1173 & 2.41 & 3.21 & 2.88 & 10 & 11 & 11 \\
\hline Switzerland & 315 & 481 & 796 & 1.91 & 1.99 & 1.96 & 13 & 12 & 12 \\
\hline Belgium & 318 & 476 & 794 & 1.92 & 1.97 & 1.95 & 12 & 13 & 13 \\
\hline Sweden & 311 & 426 & 737 & 1.88 & 1.76 & 1.81 & 14 & 16 & 14 \\
\hline Turkey & 230 & 451 & 681 & 1.39 & 1.87 & 1.67 & 16 & 14 & 15 \\
\hline Brazil & 177 & 434 & 611 & 1.07 & 1.80 & 1.50 & 18 & 15 & 16 \\
\hline India & 176 & 416 & 592 & 1.07 & 1.72 & 1.46 & 19 & 17 & 17 \\
\hline Poland & 234 & 321 & 555 & 1.42 & 1.33 & 1.36 & 15 & 20 & 18 \\
\hline Denmark & 179 & 348 & 527 & 1.08 & 1.44 & 1.30 & 17 & 19 & 19 \\
\hline Greece & 168 & 349 & 517 & 1.02 & 1.45 & 1.27 & 20 & 18 & 20 \\
\hline Total & 16,523 & 24,146 & 40,669 & & & & & & \\
\hline
\end{tabular}

$\mathrm{COPD}=$ Chronic obstructive pulmonary disease 
Indian output in COPD research has increased from 176 publications during 2003-2007 to 416 publications during 2008-2012, witnessing a growth rate of $136.36 \%$ [Table 2].

\section{INTERNATIONAL COLLABORATION}

The share of ICPs in India's total publication output in COPD was $12.67 \%$ during 2003-2012, which increased from $10.80 \%$ during $2003-2007$ to $13.46 \%$ during 2008-2012. India had collaborated with 60 countries in COPD during 2003-12 and the largest share $(53.33 \%)$ was contributed by USA, followed by UK (29.33\%), Australia (12.00\%), Germany, Canada and Switzerland (10.67\% each), France (9.33\%), Sweden, Spain, New Zealand, The Netherlands, Nepal and Italy $(6.67 \%$

Table 2: India's publication output and ICPs in COPD during 2003-2012

\begin{tabular}{lccc}
\hline Year & TP & ICP & \% ICP \\
\hline 2003 & 16 & 0 & 0.00 \\
2004 & 26 & 4 & 15.38 \\
2005 & 29 & 4 & 13.79 \\
2006 & 41 & 8 & 19.51 \\
2007 & 64 & 3 & 4.69 \\
2008 & 37 & 4 & 10.81 \\
2009 & 52 & 7 & 13.46 \\
2010 & 91 & 14 & 15.38 \\
2011 & 120 & 16 & 13.33 \\
2012 & 116 & 15 & 12.93 \\
$2003-2007$ & 176 & 19 & 10.80 \\
$2008-2012$ & 416 & 56 & 13.46 \\
$2003-2012$ & 592 & 75 & 12.67 \\
\hline
\end{tabular}

$\mathrm{TP}=$ Total publications, ICPs=International collaborative publications, $\mathrm{COPD}=$ Chronic obstructive pulmonary disease each) during 2003-2012. The ICPs share has increased by $9.03 \%$ in Australia, followed by Sweden, New Zealand, The Netherlands and Italy $(8.93 \%$ each), Germany and Switzerland (7.24\% each), France (5.45\%), UK (4.04\%), Spain and Nepal (1.88\% each), as against decrease by $6.1 \%$ in USA from 2003-2007 to 2008-2012 [Table 3].

\section{Subject-Wise Distribution}

The India's publication output in COPD during 20032012 has been published in the context of five subject sub-fields (as reflected in database classification based on journal title subject), with highest publication output coming from medicine (460 publications, $77.70 \%$ share), followed by biochemistry, genetics and molecular biology (100 publications, $16.89 \%$ ), pharmacology, toxicology and pharmaceutics (85 publications, 14.36\%), environment science (17 publications, 2.87\%) and immunology and microbiology (16 publications, 2.70\%) during 2003-2012. On further analyzing the trends in research using activity index under various sub-fields, it was found that research activity has increased in medicine (activity index from 91.40 to 103.64), biochemistry, genetics and molecular activity (activity index from 77.36 to 109.58), pharmacology, toxicology and pharmaceutics (activity index from 83.10 to 107.15), as against decrease in environment science (activity index from 138.50 to 83.71) and immunology and microbiology (activity index from 105.11 to 97.84) from 2003-2007 to 2008-2012. On analyzing the citation impact of COPD output, it was found that pharmacology, toxicology and pharmaceutics had scored the highest citation impact per paper of 6.87 , followed by immunology

Table 3: Share of various collaborating countries in India's ICPs in COPD during 2003-2012

\begin{tabular}{|c|c|c|c|c|c|c|}
\hline \multirow{2}{*}{$\begin{array}{l}\text { Collaborating } \\
\text { country }\end{array}$} & \multicolumn{3}{|c|}{ Number of ICPs } & \multicolumn{3}{|c|}{ Share of ICPs } \\
\hline & 2003-2007 & 2008-2012 & 2003-2012 & 2003-2007 & 2008-2012 & 2003-2012 \\
\hline USA & 11 & 29 & 40 & 57.89 & 51.79 & 53.33 \\
\hline UK & 5 & 17 & 22 & 26.32 & 30.36 & 29.33 \\
\hline Australia & 1 & 8 & 9 & 5.26 & 14.29 & 12.00 \\
\hline Germany & 1 & 7 & 8 & 5.26 & 12.50 & 10.67 \\
\hline Canada & 2 & 6 & 8 & 10.53 & 10.71 & 10.67 \\
\hline Switzerland & 1 & 7 & 8 & 5.26 & 12.50 & 10.67 \\
\hline France & 1 & 6 & 7 & 5.26 & 10.71 & 9.33 \\
\hline Sweden & 0 & 5 & 5 & 0.00 & 8.93 & 6.67 \\
\hline Spain & 1 & 4 & 5 & 5.26 & 7.14 & 6.67 \\
\hline New Zealand & 0 & 5 & 5 & 0.00 & 8.93 & 6.67 \\
\hline Netherlands & 0 & 5 & 5 & 0.00 & 8.93 & 6.67 \\
\hline Nepal & 1 & 4 & 5 & 5.26 & 7.14 & 6.67 \\
\hline Italy & 0 & 5 & 5 & 0.00 & 8.93 & 6.67 \\
\hline Total & 19 & 56 & 75 & & & \\
\hline
\end{tabular}

$\mathrm{COPD}=$ Chronic obstructive pulmonary disease, $\mathrm{ICPS}=$ International collaborative publication 
and microbiology (5.94), biochemistry, genetics and molecular biology (4.39), environment science (3.41) and medicine (2.94) during 2003-2012 [Table 4].

\section{Research Output by Population Age Group}

On classifying the COPD output in India by population age group during 2003-2012, it was observed that the largest share $(42.57 \%)$ comes from adults, followed by aged $(29.39 \%)$, middle-aged $(23.82 \%)$, adolescents $(5.74 \%)$ and child $(4.73 \%)$. Of these population age groups, the publication share has decreased in all categories from 2003-2007 to 2008-2012 [Table 5].

\section{Profile of Top 10 Most Productive Indian Organizations}

The total Indian research output in COPD was published from 180 organizations, of which the top 10 have published 9-43 publications each and together contributed $30.07 \%$ (178 publications) share in the Indian cumulative publications output during 2003-2012. The scientometric profile of these 10 organizations is presented in Table 6. The average publication productivity per organization reported by the top 10 organizations was 17.8 and only three organizations have registered higher publication output than the group average. These are Postgraduate Institute of Medical Education and Research, Chandigarh with 43 publications, followed All India Institute of Medical Sciences, New Delhi (33 publications) and Vallabhbhai Patel Chest Institute, New Delhi (23 publications). The average citation per paper registered by the total publications (TPs) of these 10 organizations was 3.57 during 2003-2012 and four organizations have registered higher citation impact than the group average. They are Ranbaxy Research Laboratories, Gurgaon with citation impact per paper of 10.89, followed by Institute of Genomics and Integrated Biology, New Delhi (5.85), Christian Medical College, Vellore (5.50) and All India Institute of Medical Sciences, New Delhi (4.42). The average h-index value of these 10 organizations was 4.6 and four organizations have achieved higher h-index value than the group's average. These are Postgraduate Institute of Medical Education and Research, Chandigarh with h-index value of 10 , followed by Institute of Genomics and Integrated Biology, New Delhi (7), All India Institute of Medical Sciences, New Delhi, Vallabhbhai Patel Chest Institute, New Delhi and Ranbaxy Research Laboratories, Gurgaon (6 each).

\section{Profile of Top 10 Most Productive Indian Authors}

The top 10 most productive authors in Indian research in COPD have published 10-17 publications each and together contributed $17.74 \%$ (105 publications) share in the cumulative publications output of India during 2003-2012. The scientometric profile of these 10 authors is presented in Table 7. Three authors have registered higher publication productivity per author than the group average of 10.50 of all authors: S.K. Chhabra (17 publications), S.K. Jindal (15 publications) and R. Agarwal (11 publications). Four authors

Table 4: Subject-wise break-up of Indian publications in COPD during 2003-2012

\begin{tabular}{|c|c|c|c|c|c|c|c|c|}
\hline \multirow[t]{2}{*}{ Subfield* } & \multicolumn{3}{|c|}{ Number of publications } & \multicolumn{2}{|c|}{ Activity index } & \multirow[t]{2}{*}{$\%$ TP } & \multirow[t]{2}{*}{ TC } & \multirow[t]{2}{*}{ ACPP } \\
\hline & 2003-2007 & 2008-2012 & 2003-2012 & 2003-2007 & 2008-2012 & & & \\
\hline Medicine & 125 & 335 & 460 & 91.40 & 103.64 & 77.70 & 1353 & 2.94 \\
\hline Biochemistry, genetics and molecular biology & 23 & 77 & 100 & 77.36 & 109.58 & 16.89 & 439 & 4.39 \\
\hline Pharmacology, toxicology and pharmaceutics & 21 & 64 & 85 & 83.10 & 107.15 & 14.36 & 584 & 6.87 \\
\hline Environment science & 7 & 10 & 17 & 138.50 & 83.71 & 2.87 & 58 & 3.41 \\
\hline Immunology and microbiology & 5 & 11 & 16 & 105.11 & 97.84 & 2.70 & 95 & 5.94 \\
\hline Total & 176 & 416 & 592 & & & & & \\
\hline
\end{tabular}

*There is a overlapping of papers under various subfields, due to the Scopus classification where few journals articles are classified under different sub-fields. $T P=$ Total publications, $T C=$ Total citations, $A C P P=$ Average citations per paper, $C O P D=$ Chronic obstructive pulmonary disease

Table 5: Indian publications in COPD by population age groups during 2003-2012

\begin{tabular}{|c|c|c|c|c|c|}
\hline \multirow{2}{*}{$\begin{array}{l}\text { Population } \\
\text { age group }\end{array}$} & \multicolumn{3}{|c|}{ Number of publications } & \multicolumn{2}{|c|}{ Share of publications } \\
\hline & 2003-2007 & 2008-2012 & 2003-2012 & 2003-2007 & 2008-2012 \\
\hline Adults & 87 & 165 & 252 & 49.43 & 39.66 \\
\hline Aged & 61 & 113 & 174 & 34.66 & 27.16 \\
\hline Middle aged & 59 & 82 & 141 & 33.52 & 19.71 \\
\hline Adolescent & 16 & 18 & 34 & 9.09 & 4.33 \\
\hline Child & 10 & 18 & 28 & 5.68 & 4.33 \\
\hline Total & 176 & 416 & 592 & 100.00 & 100.00 \\
\hline
\end{tabular}

$\mathrm{COPD}=$ Chronic obstructive pulmonary disease 
have registered higher citation impact per paper than the group average (5.36) of all authors during 2003-2012 during 2003-2012: A. Roy (11.89), S.G. Dastidar (9.60), S.K. Jindal (5.73) and V.K. Vijayan (5.38). Five authors have registered h-index more than the average h-index (4.50) of all authors during 2003-12: A. Roy (7), S.K. Chhabra (6), S.K. Jindal (6), S.G. Dastidar (6) and R. Agarwal (5).

\section{Mode of Communication}

Of the total 592 Indian publications on COPD, 498 publications were published in 161 journals during

\begin{tabular}{|c|c|c|c|c|}
\hline Name & TP & $\mathrm{TC}$ & ACPP & $\mathrm{H}$-index \\
\hline $\begin{array}{l}\text { Postgraduate Institute of Medical } \\
\text { Education and Research, Chandigarh }\end{array}$ & 43 & 150 & 3.49 & 10 \\
\hline $\begin{array}{l}\text { All India Institute of Medical } \\
\text { Sciences, New Delhi }\end{array}$ & 33 & 146 & 4.42 & 6 \\
\hline $\begin{array}{l}\text { Vallabhbhai Patel Chest Institute, } \\
\text { New Delhi }\end{array}$ & 23 & 77 & 3.35 & 6 \\
\hline Jawaharlal Medical College, Aligarh & 14 & 8 & 0.57 & 2 \\
\hline $\begin{array}{l}\text { Government Medical College and } \\
\text { Hospital, Chandigarh }\end{array}$ & 13 & 13 & 1.00 & 2 \\
\hline $\begin{array}{l}\text { Institute of Genomics and Integrated } \\
\text { Biology, New Delhi }\end{array}$ & 13 & 76 & 5.85 & 7 \\
\hline Christian Medical College, Ludhiana & 11 & 7 & 0.64 & 1 \\
\hline Christian Medical College, Vellore & 10 & 55 & 5.50 & 4 \\
\hline SMS Medical College, Jaipur & 9 & 6 & 0.67 & 2 \\
\hline $\begin{array}{l}\text { Ranbaxy Research Laboratories, } \\
\text { Gurgaon }\end{array}$ & 9 & 98 & 10.89 & 6 \\
\hline Total of 10 organizations & 178 & 636 & 3.57 & 3.8 \\
\hline Total of the country & 592 & & & \\
\hline $\begin{array}{l}\text { Share of top } 10 \text { organizations in } \\
\text { country total }\end{array}$ & 30.07 & & & \\
\hline
\end{tabular}

2003-2012. The list of top 10 journals along with their output is given in Table 8. The top 10 journals published 144 publications, accounting for $24.32 \%$ share of the TP output in COPD during 2003-2012. The publication share of these 10 most productive journals has increased from $15.90 \%$ during $2003-2007$ to $27.88 \%$ during 2008-2012.

\section{SUMMARY AND CONCLUSION}

USA contributed the largest share $(26.52 \%)$ among the leading countries contributing to global COPD research, followed by UK (11.83\%), Germany (6.48\%), Italy (6.44\%), Canada (5.68\%), Spain (5.29\%), The Netherlands (4.78\%), France (4.16\%), Japan (3.45\%), China (2.94\%), Australia (2.88\%), etc., India's global publication share in COPD research was $1.46 \%$ during 2003-2012, which increased from 1.07\% during 2003-2007 to $1.72 \%$ during $2008-2012$. In all 592 publications are published by Indians in COPD research during 2003-2012, registering an annual average growth rate of $30.38 \%$. In Indian COPD research, the share of ICPs was $12.67 \%$ during 2003-2012, increasing from 10.80\% during 2003-2007 to $13.46 \%$ during 2008-2012. Among the major foreign collaborators in Indian research during 2003-2012, USA contributed the largest share of $53.33 \%$, followed by UK (29.33\%), Australia (12.00\%), Germany, Canada and Switzerland (10.67\% each), France (9.33\%), etc., Medicine contributed the largest publications share $(77.70 \%)$ in Indian COPD research, followed by biochemistry, genetics and molecular biology (16.89\%), pharmacology, toxicology and pharmaceutics (14.36\%), environment science $(2.87 \%)$ and immunology and microbiology (2.70\%) during

Table 7: Scientometric profile of top 10 Indian authors in COPD 2003-2012

\begin{tabular}{|c|c|c|c|c|c|}
\hline Name & Address & TP & TC & ACPP & H-index \\
\hline S.K. Chhabra & Vallabhbhai Patel Chest Institute, New Delhi & 17 & 88 & 5.18 & 6 \\
\hline S.K. Jindal & Postgraduate Institute of Medical Education and Research, Chandigarh & 15 & 86 & 5.73 & 6 \\
\hline R. Agarwal & Postgraduate Institute of Medical Education and Research, Chandigarh & 11 & 48 & 4.36 & 5 \\
\hline A.N. Aggarwal & Postgraduate Institute of Medical Education and Research, Chandigarh & 10 & 41 & 4.10 & 4 \\
\hline A. Roy & Ranbaxy Research Laboratories, Gurgaon & 9 & 107 & 11.89 & 7 \\
\hline R. Guleria & All India Institute of Medical Sciences, New Delhi & 9 & 26 & 2.89 & 3 \\
\hline P.R. Mohapatra & Government Medical College and Hospital, Chandigarh & 9 & 5 & 0.56 & 1 \\
\hline V.K. Vijayan & Vallabhbhai Patel Chest Institute, New Delhi & 8 & 43 & 5.38 & 4 \\
\hline A. Mohan & All India Institute of Medical Sciences, New Delhi & 7 & 23 & 3.29 & 3 \\
\hline \multirow[t]{4}{*}{ S.G. Dastidar } & Ranbaxy Research Laboratories, Gurgaon & 10 & 96 & 9.60 & 6 \\
\hline & Total of 10 authors & 105 & 563 & 5.36 & 4.5 \\
\hline & Total of the country & 592 & & & \\
\hline & Share of top 10 authors in country output & 17.74 & & & \\
\hline
\end{tabular}

$\mathrm{TP}=$ Total publications, $\mathrm{TC}=$ Total citations, $\mathrm{ACPP}=$ Average citations per paper, $\mathrm{CO} \mathrm{PD}=$ Chronic obstructive pulmonary disease 
Table 8: Media of communication of Indian scientists in most productive journals in COPD research, during 2003-2012

\begin{tabular}{|c|c|c|c|}
\hline \multirow[t]{2}{*}{ Name of the journal } & \multicolumn{3}{|c|}{ Number of publications } \\
\hline & 2003-2007 & 2008-2012 & 2003-2012 \\
\hline Lung India & 0 & 35 & 35 \\
\hline $\begin{array}{l}\text { Journal of the Association of } \\
\text { Physicians of India }\end{array}$ & 6 & 16 & 22 \\
\hline $\begin{array}{l}\text { Indian Journal of Medical } \\
\text { Research }\end{array}$ & 5 & 9 & 14 \\
\hline $\begin{array}{l}\text { Indian Journal of Critical } \\
\text { Care Medicine }\end{array}$ & 4 & 7 & 11 \\
\hline Chest & 4 & 7 & 11 \\
\hline $\begin{array}{l}\text { Journal of the Indian } \\
\text { Medical Association }\end{array}$ & 4 & 7 & 11 \\
\hline $\begin{array}{l}\text { Journal of Clinical and } \\
\text { Diagnostic Research }\end{array}$ & 0 & 11 & 11 \\
\hline $\begin{array}{l}\text { Journal of Anaesthesiology } \\
\text { Clinical Pharmacology }\end{array}$ & 3 & 7 & 10 \\
\hline Annals of Thoracic Medicine & 2 & 8 & 10 \\
\hline Lancet & 0 & 9 & 9 \\
\hline Total of 10 journals & 28 & 116 & 144 \\
\hline Total of the country & 176 & 416 & 592 \\
\hline $\begin{array}{l}\text { Share of top } 10 \text { journals in } \\
\text { country output }\end{array}$ & 15.9 & 27.88 & 24.32 \\
\hline
\end{tabular}

$\mathrm{COPD}=$ Chronic obstructive pulmonary disease

2003-2012. Adults constituted the largest share (42.57\%) of Indian COPD output during 2003-2012, followed by aged $(29.39 \%)$, middle-aged $(23.82 \%)$, adolescents $(5.74 \%)$ and child $(4.73 \%)$. The 10 most productive organizations in Indian COPD research contributed $30.07 \%$ share to the cumulative publications output of India during 2003-2012 and have registered an average productivity per author of 17.8, an average citation impact per paper of 3.57 and an average h-index value of 4.60. The 10 most productive authors in Indian COPD research contributed $17.74 \%$ share to the cumulative publications output of India during 2003-2012 and have registered an average productivity per author of 10.50 , an average citation impact per paper of 5.36 and an average h-index value of 4.50 . The 592 Indian publications on COPD appeared in 161 journals during 2003-2012, of which the top 10 journals contributed $24.32 \%$ share of the total output. The share of these 10 most productive journals increased from $15.90 \%$ during $2003-2007$ to $27.88 \%$ during $2008-2012$. Compared to the mortalities in India because of COPD, the present Indian research efforts are very small. Therefore, India needs to increase its research efforts substantially, improve its research quality and increase its international collaborative research efforts. In addition, India needs a National COPD Prevention and Control Programme, with a major thrust on: (a) Setting up appropriate healthcare services infrastructure in India for early and accurate diagnosis, appropriate treatment and rehabilitation programmes, (b) generating new knowledge in COPD that will be relevant to India's needs through properly designed and funded research studies and (c) dissemination of knowledge regarding prevention, diagnosis, treatment and rehabilitation to healthcare providers in India so that they can improve the quality of care of patients with COPD. For this, physicians, researchers, policy makers, medical educators and healthcare providers will need to come together, devise and implement strategies that will be effective and sustainable.

\section{REFERENCES}

1. Respiratory diseases; 18 June, 2014. Available from: http://www. en.wikipedia.org/wiki/Respiratory-disease. [Last accessed on 2014 Jun 19].

2. Jindal SK, Gupta D, Aggarwal AN. Chronic Obstructive Pulmonary Disease (COPD) in India: A Guide for Physicians; 2003. Available from: http://www.medind.nic.in/iae/to4/i2/1aet04i2p137.pdf. [Last accessed on 2014 Jun 19].

3. Jindal SK. COPD: The unrecognized epidemic in India. J Assoc Physicians India 2012;60 Suppl: 14-6.

4. Sundeep S. Conquering COPD: A Collective Effort. Express Healthcare; November 09, 2013. Available from: http://www.healthcare.financialexpress.com/ it-healthcare/2144-conquering-copd-a-collective-effort. [Last accessed on 2014 Jun 19].

5. Global Initiative for Chronic Obstructive Lung Disease. Pocket Guide to COPD Diagnosis, Management and Prevention. A Quide to Health Care Professionals. Available from: http://www.goldcopd. org/uploads/user/files/GOLD_Pocket_Jan 30.pdf. [Last accessed on 2014 Jun 19; Last updated on 2014 Jun 11].

6. WHO. Burden of COPD; 2014. Available from: http://www.who.int/ respiratory/copd/burden/en/. [Last accessed on 2014 Jun 19].

7. Koul PA. Chronic obstructive pulmonary disease: Indian guidelines and the road ahead. Lung India 2013;30:175-7.

8. García-Río F, Serrano S, Dorgham A, Alvarez-Sala R, Ruiz Peña A, Pino JM, et al. A bibliometric evaluation of European Union research of the respiratory system from 1987-1998. Eur Respir J 2001;17:1175-80.

9. Rippon I, Lewison G, Partridge MR. Research outputs in respiratory medicine. Thorax 2005;60:63-7.

10. Groneberg-Kloft B, Scutaru C, Dinh QT, Welte T, Chung KF, Fischer A, et al. Inter-disease comparison of research quantity and quality: Bronchial asthma and chronic obstructive pulmonary disease. J Asthma 2009;46:147-52.

11. Chen SR, Chiu WT, Ho YS. Asthma in children: Mapping the literature by bibliometric analysis. Revue Francaise d'Allergologie et d' Immunologie Clinique 2005;45:442-6.

12. Gupta BM, Bala A. Mapping of asthma research in India: A scientometric analysis of publications output during 1999-2008. Lung India 2011;28:239-46.

How to cite this article: Gupta R, Gupta BM, Mueen M. Chronic obstructive pulmonary disease: A scientometric analysis of Indian publications during 2003-2012. J Sci Res 2014;3:61-7.

Source of Support: Nil, Conflict of Interest: None declared 